J. Phys. Earth, 44, 357-372, 1996

\title{
Two-Dimensional Analysis of Gravity Anomaly across the Rokko Fault System
}

\author{
Shigeki Kobayashi, ${ }^{1, *}$ Shigeo Yoshida, ${ }^{1}$ Shuhei Okubo, ${ }^{1}$ \\ Ryuichi Shichi, ${ }^{2}$ Toshihiko Shimamoto, ${ }^{1}$ and Teruyuki Kato ${ }^{1}$ \\ ${ }^{1}$ Earthquake Research Institute, The University of Tokyo, Bunkyo-ku, Tokyo 113, Japan \\ ${ }^{2}$ Department of Earth and Planetary Sciences, School of Science, Nagoya University, \\ Chikusa-ku, Nagoya 464-01, Japan
}

\begin{abstract}
We carried out dense gravity measurements with the Fast Static GPS positioning along five survey lines across the Rokko fault system. We calculated the Bouguer anomaly to estimate the underground structure relevant to the 1995 Hyogo-ken Nanbu earthquake. We applied the two-dimensional Talwani's method to the modeling, assuming that the density structure is similar for all the five survey lines. All the Bouguer anomaly profiles are characterized by flat areas on the Rokko Mountains and Kobe Plain, with steep gradient between them. The gradient is most likely due to the fault scarps between the Rokko granite and the sedimentary layer of the Osaka and Kobe groups. It also indicates that the faults are vertical or reverse ones, at least just below their surface traces. This finding is consistent with the tectonic background of the Rokko Mountains that have upheaved under the east-west compression in the Quaternary. Moreover, we found the southwestward extension of the Koyo Fault underneath the sedimentary layer. The extension runs on the edge of the earthquake disaster zone. We inferred that the thickness of the sedimentary layer is $1-2 \mathrm{~km}$ near the sea, decreasing gradually toward the mountain side. The wedge-like structure and the hidden fault under the Kobe Plain may have served as a focusing lens of seismic rays during the earthquake.
\end{abstract}

\section{Introduction}

The Hyogo-ken Nanbu earthquake occurred on January 17, 1995. The seismic fault extends from Awaji Island through Kobe and Ashiya Cities to Nishinomiya and Takarazuka Cities. The fault reaches to the ground surface on Awaji Island (e.g., Nakata et al., 1995). On the Honshu side, however, the surface trace of the fault has not been discovered, although seismic records, distributions of aftershocks, and geodetic observations (e.g., Kikuchi, 1995a; Kamae and Irikura, 1995; Hashimoto, 1995) indicate fault motion there. This fact implies that the fault moved underground but did not reach to the surface. Thus the relation between the seismic fault and the known fault system in the Rokko area has been a major subject of debates.

One of the authors (TS) noticed just after the earthquake that the most heavily stricken area is confined within a narrow belt of about $3 \mathrm{~km}$ wide and $25 \mathrm{~km}$ long extending from Suma-ku, Kobe City to Nishinomiya City (Shimamoto, 1995). He argued that this belt agrees with the extension of the seismic fault, and that this fault is a natural extension of the Gosukebashi, Ashiya and Koyo Faults. In other words, the Gosukebashi, Ashiya and Koyo Faults can be regarded as branch faults of the seismic fault (Fig. 1). However, the disaster belt can also be interpreted to be due to the structure of the sedimentary layer of the Osaka and Kobe groups (Fig. 2) (e.g., Ishikawa et al., 1995). The wedge-like structure of the soft layer may serve as a focusing lens of seismic waves (e.g., Shichi and Aoki,1995; Pitarka et al., 1996). Moreover, the seismic fault may be the extension of the well-known Suma and Suwayama Faults, which did not appear to move at ground level during the earthquake.

The purpose of this paper is to reveal the underground structure of the Kobe district by gravity measurement. Gravity can be measured at many points, and therefore provides information on the underground structure over a large area.

Received July 15, 1995; Accepted November 25, 1995

* To whom correspondence should be addressed. 


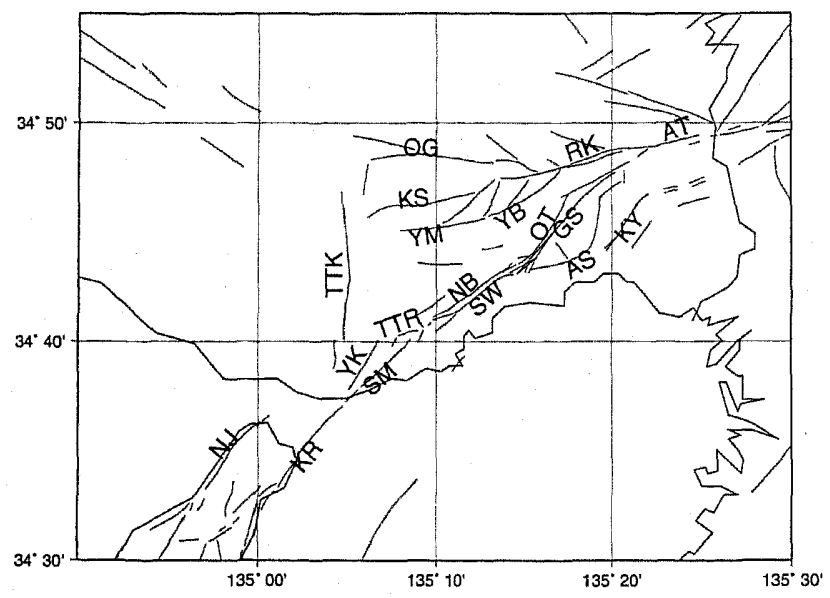

Fig. 1. Rokko fault system, The names of the faults are abbreviated as follows. AT, Arima-Takatsuki tectonic line; AS, Ashiya Fault; GS, Gosukebashi Fault; KR, Kariya Fault; KS, Kashiodani Fault; KY, Koyo Fault; NB, Nunobiki Fault; NJ, Nojima Fault; OG, Oogo Fault; OT, Ootsuki Fault; RK, Rokko Fault; SM, Suma Fault; SW, Suwayama Fault; TTK, Takatsukayama Fault; TTR, Takatoriyama Fault; YB, Yubunedani Fault; YK, Yokooyama Fault; YM, Yamada Fault. The seismic fault of the Hyogo-ken Nambu earthquake approximately runs from NJ through SM, SW, and GS to AT.

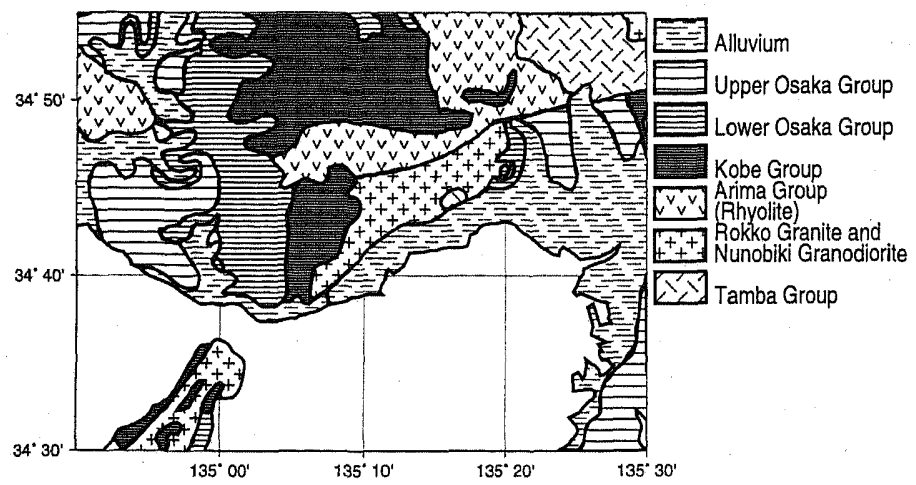

Fig. 2. Geological map around the Rokko Mountains. The Tamba group consists of Mesozoic sedimentary and metamorphic rocks. The Rokko granite, the Nunobiki granodiorite, and the Arima rhyolite formed in Cretaceous. They are the basement rocks in the Kobe-Awaji area. The Kobe and Osaka groups are Tertiary and Quaternary sediments.

Furthermore, electromagnetic and seismic explorations are not suitable because the relevant area is highly urbanized. We set five survey profiles from the coast up to the mountain area perpendicular to the Rokko Mountains (Fig. 3). The directions of the profiles are suited to the two-dimensional Talwani method (Talwani et al., 1959) for investigating underground density structure, because the geological structure of the Rokko and Kobe areas is almost uniform along the direction of the Rokko Mountains and the coastline. We constructed the density structure across the Rokko Mountains, thus contributing to the solving of the problems explained above.

A gravity survey was also conducted by the Geological Survey of Japan in this area after the earthquake (Endo et al., 1995). Their main purpose was to study the underground structure of the stricken area, namely, the flat land along the coastline. In contrast, our purpose was to study the 


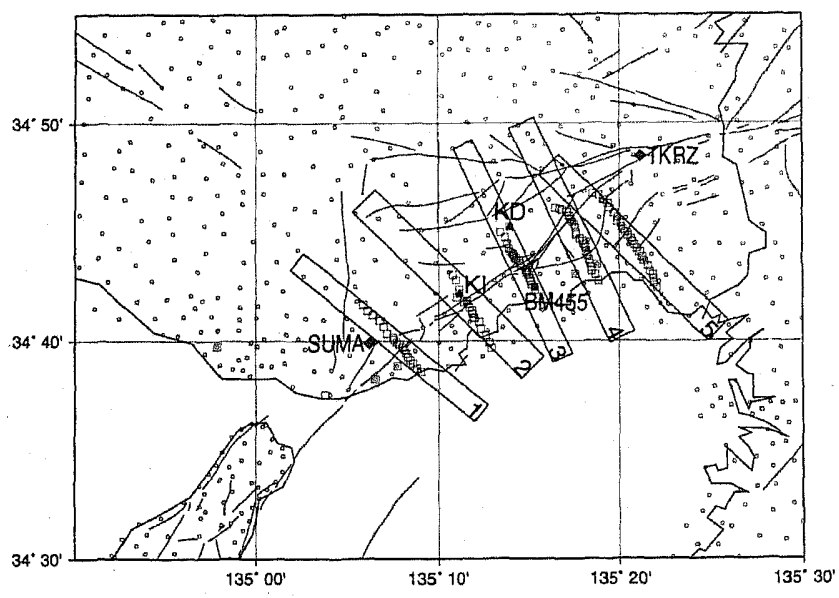

Fig. 3. Locations of the gravity and GPS measurement points with five survey lines used for density modeling. The five numbered rectangles denote areas used for making profiles and density modeling. Each profile is named as follows. 1, NAGATA; 2, SANNOMIYA; 3, ISHIYAGAWA; 4, ASHIYAGAWA; 5, NISHINOMIYA. Open squares denote gravity measurement points in this survey. The solid square denotes the reference point of our gravity measurements, benchmark BM455. Open circles denote gravity points measured previously and compiled by one of the authors (RS) (Gravity Research Group in Southwest Japan, 1994). Solid triangles denote triangulation points used as height references in the coordinate transformation from WGS84 to Tokyo Datum (KD, Kinenhidai; KI, Kuchiichiri). Solid diamonds denote reference GPS points used in the fast static method (TKRZ, Takarazuka; SUMA, Suma).

structure across the Rokko Mountains.

The structure beneath the Rokko area is also a key to a better understanding of the mechanism and history of the Rokko Mountains formation or "Rokko Movements" (Ikebe and Huzita, 1966; Huzita, 1968). The granitic Rokko Mountains are known to have risen under the east-west compressional stress field in the Quaternary (e.g., Huzita et al., 1971). The rising Rokko Mountains and the sunken Osaka Bay are separated by the Rokko fault system (Fig. 2). The relative vertical movement amounts to about $1,000 \mathrm{~m}$, and the average relative vertical velocity is about $1,000 \mathrm{~m} / \mathrm{My}$ $(\approx 1 \mathrm{~m} / 1,000 \mathrm{y})$. The Rokko fault system consists of many parallel faults with strikes in the NE-SW direction. The southern side of the faults are covered with thick sedimentary layers, called the Osaka and Kobe groups (Fig. 2). Three questions arise concerning this fault system. 1) How many parallel faults exist in the fault system? Many faults are already known geologically, but some faults may exist below Kobe's urbanized area; these faults may be covered with the thick sedimentary layer, and may not reach to the ground surface. The seismic fault of the Kobe earthquake may be one of the unknown faults. 2) Did the faults move simultaneously during an earthquake or independently during different earthquakes? This question is related to the physics of rupture in general. One may imagine intuitively that one rupture plane moves in one earthquake event, because rupture is an unstable positive feedback phenomenon. 3) Is the displacement of $1,000 \mathrm{~m}$ distributed among the faults, or does a major fault exist? This problem is related to the history of the Rokko Mountains formation. For example, there are four faults along the southeast boundary of the Rokko Mountains, namely, the Otsuki, Gosukebashi, Ashiya, and Koyo Faults, but the relation among them are yet unclear. The present gravity survey cannot answer all the questions above, but present a clue to the solutions.

This paper is composed of 4 sections as follows. We present the method of gravity measurement and survey in Sec. 2. The analysis of the underground structure is given in Sec. 3. In Sec. 4, we give conclusions and discussion. 


\section{Gravity Measurement and Positioning}

\subsection{Procedure of gravity measurement}

We established 115 gravity points along five profiles by using a LaCoste \& Romberg model $G$ gravimeter with reference to benchmark BM455 $(H=3.6 \mathrm{~m}, g=979,697.80 \mathrm{mgal})$ in Higashi-Nada-ku (Fig. 3). Gravity measurements were carried out on a daily basis using the closed loop method. Misclosure was kept below $80 \mu \mathrm{gal}$, which arose from instrumental drift. Unpublished data of one of the authors (RS) are merged in the present database (Gravity Research Group in Southwest Japan, 1994).

\subsection{Positioning by the fast static GPS}

\subsubsection{Technical overview}

Homogeneous and dense distribution of gravity points is essential to produce an accurate Bouguer gravity anomaly map. We should recall here that we must determine the horizontal and vertical (referred to the mean sea level) coordinates besides gravity values to compute the Bouguer anomaly. Although topography maps of the Geographical Survey Institute (GSI) are readily available, we are often forced to determine 3-D positions by ourselves when we find few points of known height. During our gravity survey after the earthquake, local municipal maps, which usually supplement the GSI maps, were not available because the city hall was severely damaged and the city office was busy in taking care of the earthquake victims. This posed a serious problem for our gravity surveying because conventional positioning (leveling and EDM measurement) is very time consuming as well as expensive. It was natural then to use the Global Positioning System (GPS) for faster and easier 3-D positioning.

Table 1 shows various schemes of the GPS posi- tioning. We chose the Fast Static GPS method introduced by Beutler et al. (1990) because it met the following requirements:

1) GPS observations at each point should be completed in a short time while one is doing gravity measurement (less than $15 \mathrm{~m}$ ).

2) It should give 3-D coordinates with accuracy of 1 to $2 \mathrm{~m}$ To estimate gravity anomaly as accurate as $0.5 \mathrm{mgal}$, the height of each gravity station should be determined with an accuracy of $2 \mathrm{~m}$ or better.

3) It should give reasonable results even if phase lock to satellites is not maintained during roving between gravity stations.

The Fast Static GPS, however, has its own limitation. Its essential role in resolving ambiguities in the phase of GPS carrier signals becomes more difficult as we process a baseline longer than $50 \mathrm{~km}$ (Hofmann-Wellenhof et al., 1992). Fortunately, we could use the GPS data taken at sites within $30 \mathrm{~km}$ distance from our survey area: Takarazuka and Suma (Fig. 3). These were two of the GPS stations where data were taken $24 \mathrm{~h}$ a day with the same GPS receivers as our Trimble model 4000 SSE. They were deployed by the Japan University Consortium for GPS Research after the earthquake from January, 1995.

We resolved all phase ambiguities when more than 3 satellites were tracked in good geometry for 8 to $20 \mathrm{~min}$.

\subsubsection{Coordinate transformation: WGS84 to Tokyo Datum}

Collected GPS data were processed by using a commercial software program, GPSurvey (Trimble Navigation, 1992), to yield baseline vectors to each master station. The software provided us with coordinates in the World Geodetic System 84 (WGS84). A problem arises here in that the Japanese geodetic system (Tokyo Datum) deviates significantly $(500 \mathrm{~m})$ from the WGS84 system. We had

Table 1. Schemes of GPS.

\begin{tabular}{|c|c|c|c|c|}
\hline & Observation time & Accuracy & No. of receivers & Requirement \\
\hline Point Positioning & Real-time & $10-100 \mathrm{~m}$ & 1 & None \\
\hline Static GPS & $>1 \mathrm{~h}$ & $\mathrm{~mm}$ & 2 & None \\
\hline Pseudo Static GPS & $10 \mathrm{~min}$ & $\mathrm{~cm}$ & 2 & $\begin{array}{l}\text { Site revisiting with time } \\
\text { difference }>1 \mathrm{~h}\end{array}$ \\
\hline Kinematic GPS & Real-time & $\mathrm{mm}$ & 2 & $\begin{array}{l}\text { No tracking interruption } \\
\text { during transportation }\end{array}$ \\
\hline Fast Static GPS & 8 to $20 \mathrm{~min}$ & $\mathrm{dm}$ & 2 & None \\
\hline
\end{tabular}


Table 2. Three-dimensional coordinates of triangulation points determined with the Fast Static GPS.

\begin{tabular}{|c|c|c|c|}
\hline Site name & Latitude & Longitude & Height (m) \\
\hline Kuchi-ichiri (KI) & $\begin{array}{c}34^{\circ} 42^{\prime} 10.678^{\prime \prime} \mathrm{N} \\
\left(34^{\circ} 42^{\prime} 10.689^{\prime \prime} \mathrm{N}\right)\end{array}$ & $\begin{array}{c}135^{\circ} 11^{\prime} 08.746^{\prime \prime} \mathrm{E} \\
\left(135^{\circ} 11^{\prime} 08.765^{\prime \prime} \mathrm{E}\right)\end{array}$ & $\begin{array}{c}339.67 \\
(337.52)\end{array}$ \\
\hline Kinenhi-dai (KD) & $\begin{array}{c}34^{\circ} 45^{\prime} 12.596^{\prime \prime} \mathrm{N} \\
\left(34^{\circ} 45^{\prime} 12.602^{\prime \prime} \mathrm{N}\right)\end{array}$ & $\begin{array}{c}135^{\circ} 13^{\prime} 58.550^{\prime \prime} \mathrm{E} \\
\left(135^{\circ} 13^{\prime} 58.558^{\prime \prime} \mathrm{E}\right)\end{array}$ & $\begin{array}{l}797.61 \\
(796.0)\end{array}$ \\
\hline
\end{tabular}

Values in the parentheses are the results published by the Geographical Survey Institute with conventional surveying.

to transform coordinates in the WGS84 to those in Tokyo Datum so that all the gravity points have coordinates in an unified system. We used a software program called TKY2WGS (Tobita, 1994) for such transformation. It claims to have an overall accuracy of $1 \mathrm{~m}$ in horizontal position and $1.3 \mathrm{~m}$ in orthometric height, which was acceptable for our present purposes.

\subsubsection{Evaluation of accuracy}

Since the Fast Static GPS is one of the most recent techniques, it was necessary to confirm the claimed accuracy (better than $1 \mathrm{~m}$ ). Therefore, we compared horizontal and vertical coordinates of two triangulation points determined by the Fast Static GPS, followed by the coordinate transformation, with those provided by the Geographical Survey Institute (Table 2). As shown in Table 2, the differences are $0.5 \mathrm{~m}$ or less in the horizontal direction and 1.6 to $2.0 \mathrm{~m}$ in height. The rather large discrepancy between the results on height is not surprising because the transformation software is purely empirical without explicit consideration of the geoidal undulation. In order to remove the systematic error of unknown sources, we reduced all the transformed heights by subtracting the averaged difference of $1.8 \mathrm{~m}$. Seventy-three points were determined in this way by using the Fast Static GPS.

\section{Analysis}

\subsection{Data processing}

Measured gravity $g$ is reduced to the Bouguer anomaly $g_{\mathrm{b}}$ by

$$
g_{\mathrm{b}}=g-\gamma+\beta \cdot h-\mathrm{Bc}+\mathrm{Tc}+\mathrm{Atm},
$$

where $\gamma$ and $\beta=0.3086 \mathrm{mgal} / \mathrm{m}$ denote the normal gravity and its vertical gradient, $h$ the station height, $\mathrm{Bc}$ the Bouguer correction, Tc the terrain correction, and Atm the atmospheric correction, respectively. The normal gravity was calculated by using the international gravity formula of 1980 . As the normal

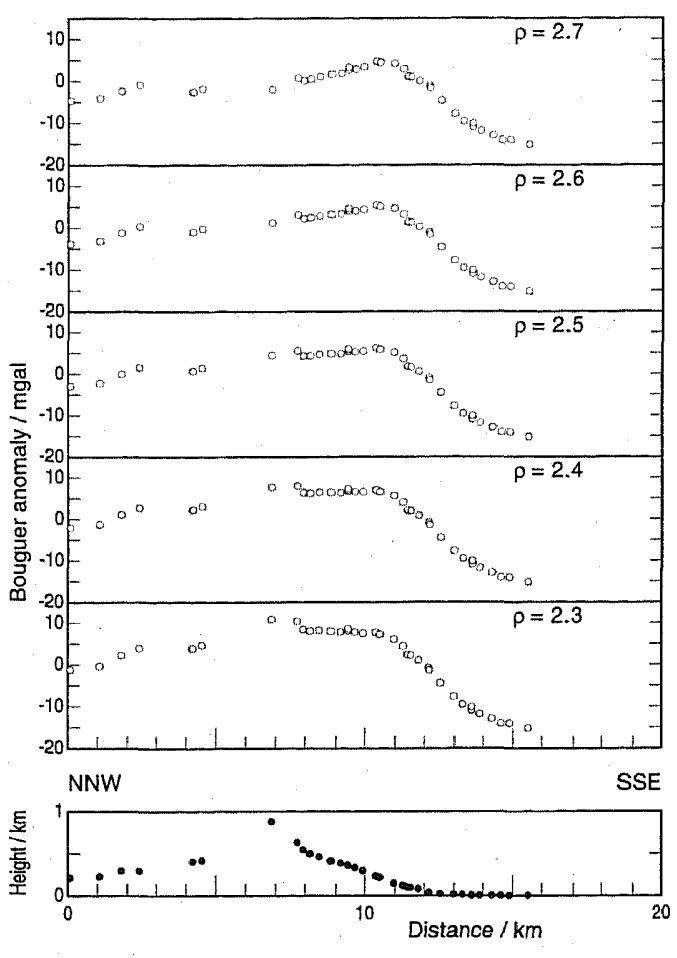

Fig. 4. Bouguer anomalies of the ASHIYAGAWA profile for the assumed densities of 2.70, 2.60, $2.50,2.40$, and $2.30 \mathrm{~g} / \mathrm{cm}^{3}$, from top to bottom. The bottom figure shows the heights of the measurement points. We set the assumed density to be $2.40 \mathrm{~g} / \mathrm{cm}^{3}$, because the Bouguer anomaly is the flattest among the four anomalies in the Rokko granitic area, where we expect massive basement with no conceivable structure.

gravity value includes the attraction of air mass, atmospheric correction Atm was applied as Atm $=0.87-0.0000965 h$ (mgal). Spherical Bouguer correction (Hagiwara, 1975) and spherical terrain correction over finite land areas were calculated after Yamamoto et al. (1982). 


\subsection{Determination of optimum surface density}

We must pay special attention to choosing the optimum surface density $\rho$ needed to calculate the Bouguer and terrain corrections. Improper $\rho$ by $\pm 0.2 \mathrm{~g} / \mathrm{cm}^{3}$ will cause a change in the Bouguer anomaly as large as $\pm 8 \mathrm{mgal}$ at a $1,000 \mathrm{~m}$-high station in the Rokko Mountains. To clarify this point, we show sets of Bouguer anomalies against several assumed densities on the ASHIYAGAWA gravity profile (Fig. 4). When we assume $\rho \geq$ $2.50 \mathrm{~g} / \mathrm{cm}^{3}$, we clearly observe negative correlation between the topography $H$ and the Bouguer anomaly $g_{\mathrm{b}}$ around the top of the mountain while $\rho \leq 2.30 \mathrm{~g} / \mathrm{cm}^{3}$ yields apparent positive correlation. In reality, we expect that the Bouguer anomaly should be flat around the ridge (for the range 7-9 km in Fig. 4) without significant $g_{\mathrm{b}}-H$ correlation because the igneous Rokko granitic body must be homogeneous with little density variation within. It follows from Fig. 4 that an optimum density is $\rho=2.40 \mathrm{~g} / \mathrm{cm}^{3}$, which is lower than the average density of fresh granite, $2.67 \mathrm{~g} / \mathrm{cm}^{3}$. Apparently low surface density for Rokko granitic rocks, however, is supported by geological evidence that they are heavily crushed and deeply weathered by Qua- ternary tectonic movements. In addition, abundant groundwater reserves may exist beneath the Rokko Mountains, which produces the famous mineral drinking water.

The resulting Bouguer anomalies with the terrain corrections for our measurements are listed in Table 6.

\subsection{Regional Bouguer anomaly and the Rokko fault system}

We first show the Bouguer anomaly map in the Rokko area including Awaji Island, the Rokko Mountains, the Osaka Plain and the Sanda Basin in Fig. 5. We drew contour lines by using the grid data calculated by a least squares smoothing method (Inoue, 1986). The contour interval is $1 \mathrm{mgal}$. Figure 1 shows active faults (Research Group for Active Faults in Japan, 1992). These two maps reveal the following interesting and important features.

1) A distinctive belt of steep gravity gradient extends from Awaji Island through the south-east flank of the Rokko Mountains to the ArimaTakatsuki tectonic line. It is steepest along the Rokko fault system: the Suma, Suwayama, Ashiya and Koyo Faults, which are expected to be major

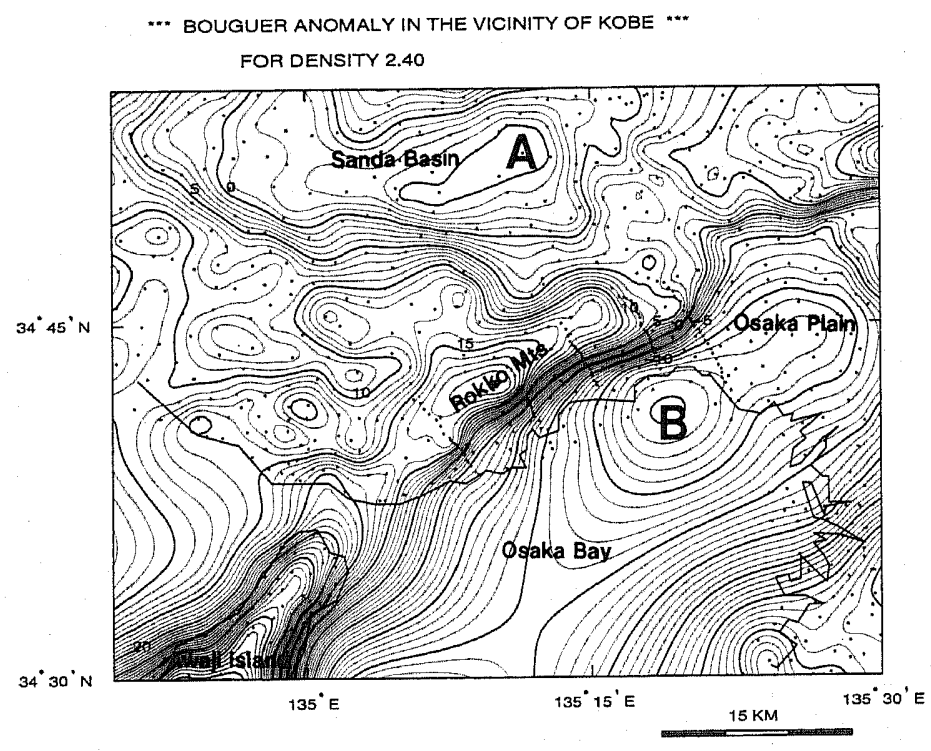

Fig. 5. Bouguer anomaly map around the Rokko Mountains with the assumed density being $2.40 \mathrm{~g} / \mathrm{cm}^{3}$. Data by Gravity Research Group in Southwest Japan (1994) are merged with those by the present measurements. Some important names of places are shown. A and B indicate centers of low anomalies (see text for details). 
reverse faults. This steep gradient belt bends at two points. One is around the junction of the Ashiya and Koyo Faults and the other is the junction of the Ashiya Fault and the Arima-Takatsuki tectonic line. The Rokko fault system is thus composed of at least three segments. In the northern part of the Awaji Island, two steep gradient belts run along both west and east coasts. The west one corresponds to the Nojima Fault, which moved at the ground surface level during the 1995 Hyogo-ken Nanbu earthquake (e.g. Nakata et al., 1995). In the vicinity of the Arima-Takatsuki tectonic line, seismic activity is clearly bounded by the corresponding steep gradient belt (Ito et al., 1989).

2) High Bouguer anomalies appear in the region of igneous rocks (Rokko granite and Arima group in Fig. 2). The highest anomaly occurs on the Rokko granitic rocks. In contrast, two major negative Bouguer anomalies (A and B in Fig. 5) in Osaka Bay and Sanda Basin correspond to sedimentary rocks, between which the large anomaly of the Rokko granitic rocks exists. It is of particular interest that the gravity features are well explained in terms of the geological history proposed by Huzita et al. (1971):

a) The Kobe group of sedimertary layers (Sanda Basin) were laid down in shallow water during the Miocene.

b) Upheaval of the Rokko Mountains which followed resulted in terraces in the Sanda Basin.

c) Subsequent subsidence of the Osaka Basin has been in progress during the Quaternary.

3) A gravity plateau running in the direction of SW-NE from Awaji Island through the Rokko Mountains to the Arima-Takatsuki tectonic line is dipping northeastward, with a horizontal gradient of $0.5 \mathrm{mgal} / \mathrm{km}$. This implies that the deep and high density basement beneath the Rokko Mountains dips in the same direction. On the other hand, the height of the Rokko Mountains increases northeastward. This negative correlation between the height and the gravity anomaly suggests isostatic adjustment operating underneath the Rokko granite.

\subsection{Two-dimensional forward modeling of subsur- face structure}

Let us next focus our attention on the Bouguer gravity anomaly along the five gravity profiles across the Rokko Mountains (Fig. 6): 1, NAGATA; 2, SANNOMIYA; 3, ISHIYAGAWA; 4, ASHIYA-
GAWA; and 5, NISHINOMIYA survey lines. All these gravity profiles have the following features in common.

1) High gravity plateau around the Rokko Mountains.

2) Gradual decrease in Bouguer anomaly toward the northwest of the Rokko Mountains, where the terrain is covered with the sediments of the Kobe group.

3) Steep gravity slope above the Rokko Fault system dipping toward the coast.

4) Low Bouguer anomaly to the east of Rokko Mountain, where thick light sediments (Osaka and Kobe groups and alluvium) and seawater of the Osaka Bay exist.

In order to explain all of the above features, we assumed that the subsurface structure is composed of four units: the Rokko granite, the Kobe (and possibly Arima) group of the northwest side of the Rokko Mountains, the Osaka and Kobe groups of the southeast side of the Rokko Mountains, and the seawater. To overcome the inherent non-uniqueness of gravity inversion, we first estimated the density of each body. We assign $2.40 \mathrm{~g} / \mathrm{cm}^{3}$ for the density of the Rokko granite as described in Sec. 3.2.

The density of the Osaka and Kobe groups lying in the southeast side of the Rokko Mountains is estimated to be $2.03 \mathrm{~g} / \mathrm{cm}^{3}$ to satisfy boring data on the depth of the granitic basement: $1.8 \mathrm{~km}$ deep near Port Island on the SANNOMIYA survey line (distance $=15 \mathrm{~km}$ in Fig. 6(b)). The density value $\rho=2.03 \mathrm{~g} / \mathrm{cm}^{3}$ is used throughout this study for the Osaka and Kobe groups along the five gravity profiles.

The density of the Kobe group lying on the northwest side of the Rokko Mountains is estimated by taking geological information into account. We take $\rho=2.10 \mathrm{~g} / \mathrm{cm}^{3}$ for this unit, because the Kobe group is older than the Osaka group and would be denser. This structure unit would include some portions of the Arima rhyolite, which should be denser than the sediments. Although there remains some ambiguity on its density, it has no critical effect on estimating subsurface structures beneath the Rokko fault system.

The density of the seawater is obviously 1.03 $\mathrm{g} / \mathrm{cm}^{3}$.

Once we determine the densities of the relevant structural units, we may infer the subsurface structure by applying Talwani's method (Talwani et al., 1959) to our five gravity profiles. We have 
S. Kobayashi et al.

(a)
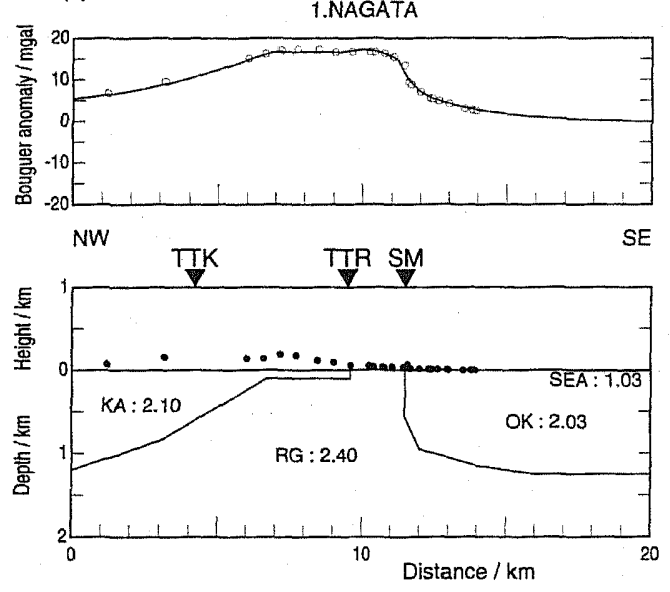

(c)

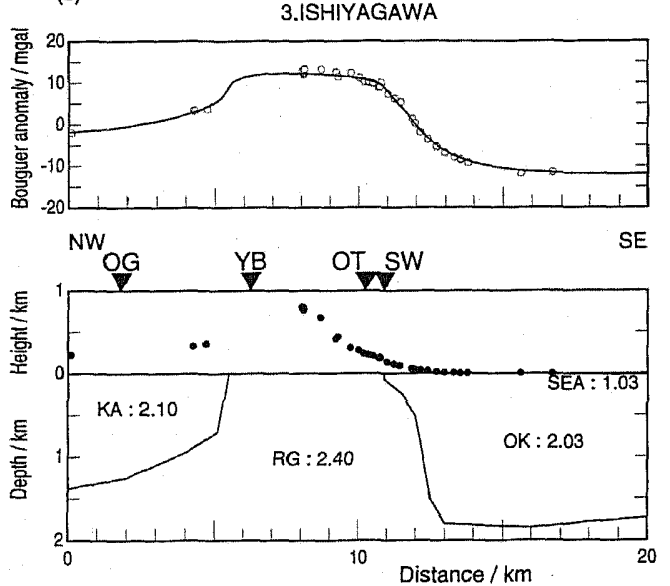

(b)
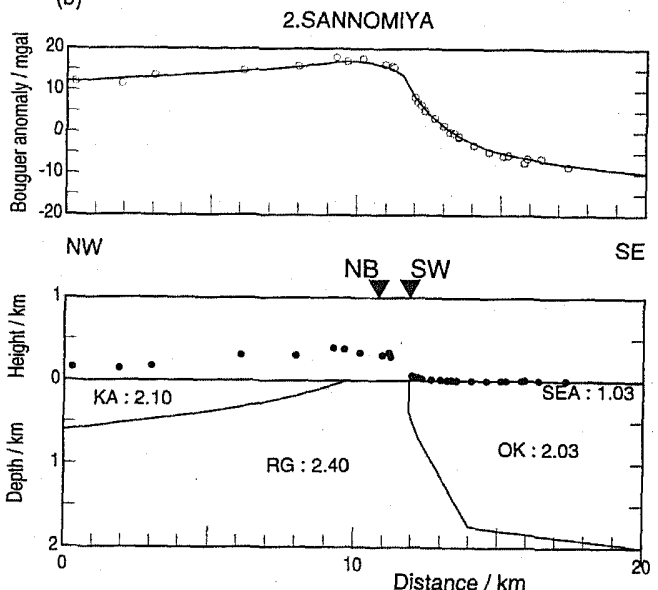

(d)
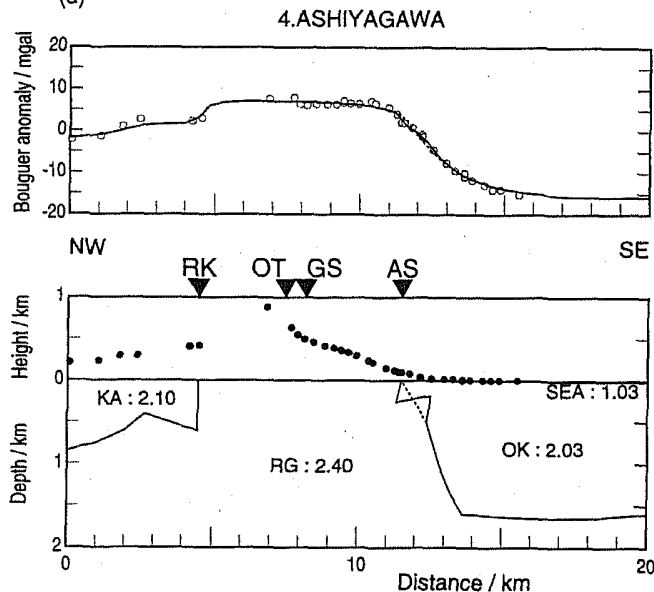

(e)

5.NISHINOMIYA

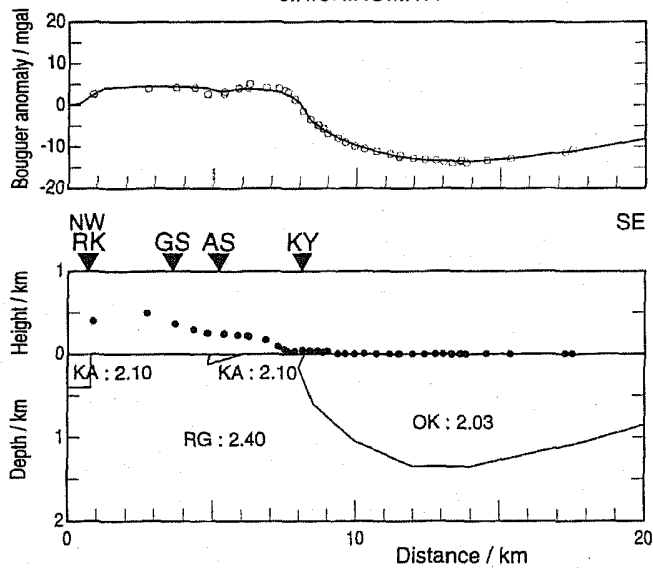

Fig. 6 
adopted the procedures described below in forward gravity modeling.

1) Fix boundaries between structural units, in particular, surface traces of the major Rokko faults.

2) Find depth and dip angles for faults with surface traces so that differences between observed and computed gravity anomalies should be minimized.

3) If necessary, consider parallel subsurface faults.

After trial and error we found the optimum structure model for each profile (Fig. 6 ). Standard deviations of the residuals are 0.4 to $0.7 \mathrm{mgal}$ (see the caption of Fig. 6).

We briefly describe below the important structural features.

1) NAGATA survey line: Bouguer gravity shows the largest horizontal gradient (>10 $\mathrm{mgal} / \mathrm{km}$ ) just above the Suma Fault. The large gradient indicates that the fault is vertical and deep. We found that the vertical offset of the fault is $550 \mathrm{~m}$.

2) SANNOMIYA survey line: We constrained the depth to the basement at three points using a priori information of boring data (Motosaka and Nagano, 1995): $720 \mathrm{~m}$ deep at Ninomiya (distance $=12 \mathrm{~km}$ in Fig. 6(b)), $1 \mathrm{~km}$ deep at the coast (distance $=13 \mathrm{~km}$ ) and $1.8 \mathrm{~km}$ deep at Port Island (distance $=15 \mathrm{~km}$ ). The boundary between the Rokko granite and Osaka group (RG and OK in Fig. 6(b)) derived from the constraints above explains very well the gentle slope of the Bouguer anomaly at distance $>12 \mathrm{~km}$ in Fig. 6(b). The Suwayama Fault at distance $=12 \mathrm{~km}$ must be either a vertical or a reverse fault. The steepness of the gravity gradient on the south-east side of the fault rejects the possibility of a normal fault. The vertical displacement is estimated to be $380 \mathrm{~m}$ on the assumption of a vertical fault just below the surface trace.

3) ISHIYAGAWA survey line: This survey line runs just across the junction of the Rokko fault system (Figs. 1 and 3), where many faults - the Uzugamori, Gosukebashi, Suwayama, Nunobiki and Otsuki Faults branch and a more complex structure may be buried (distances of $9.8-11.4 \mathrm{~km}$ in Fig. 6(c)). Therefore, a simple fault model extending smoothly to depth fails in explaining gravity so long as we fix the surface trace to any fault above. We found that a structure with a hidden fault scarp at distance $=11.5-12 \mathrm{~km}$ and depth $=$ 240-500 m (Fig. 6(c)) explains the gravity anomaly very well.

4) ASHIYAGAWA survey line: Two gravity steps are clearly visible in Fig. 6(d) at distance $=11.5 \mathrm{~km}$ and at distance $=12.0 \mathrm{~km}$. The first step is explained well by the Ashiya Fault, which is inferred as a reverse one, while the second step suggests existence of a hidden reverse fault at a depth of several hundred meters (solid line in Fig. $6(d))$. On the other hand, any other structure with no hidden fault yields poorer agreement with the observations; we calculated the gravity for several types of shallow subsurface structures (Fig. 7(a)). Table 3 shows the comparison of the variances for each model. It is clear that existence of a hidden fault significantly reduces the variance of residuals. The solid line in Fig. 6(d) indicates an optimum model (Model A-B-C-D), while, for example, Model A-D cannot explain well the observed two gravity steps (broken line in Fig. 6(d)). The depth of the subsurface fault was estimated on careful comparison among several assumed depths of points $B$ and

Fig. 6. Measured and calculated Bouguer anomalies along the five survey lines with the assumed density being $2.40 \mathrm{~g} / \mathrm{cm}^{3}$. (a) Line 1: NAGATA. (b) Line 2: SANNOMIYA. (c) Line 3: ISHIYAGAWA. (d) Line 4: ASHIYAGAWA. (e) Line 5: SANNOMIYA. Minimum values of the standard deviation for each model are $0.370,0.513,0.557,0.654$ and 0.518 , respectively. The top figures show the Bouguer anomalies. Open circles denote measured values. Solid curve denotes anomaly calculated using the two-dimensional Talwani method (Talwani et al., 1959) with the density structure shown in the bottom figures. In (d), broken lines show the structure without a step and the gravity anomaly calculated thereby for comparison. The fit to the observation is worse than the structure with a step and a hidden fault (solid line). The following abbreviations are used to denote geological units. RG: Rokko granite and Nunobiki granodiorite $\left(\rho=2.40 \mathrm{~g} / \mathrm{cm}^{3}\right)$. OK: Osaka and Kobe groups $\left(\rho=2.03 \mathrm{~g} / \mathrm{cm}^{3}\right)$. KA: Kobe and Arima groups $\left(\rho=2.10 \mathrm{~g} / \mathrm{cm}^{3}\right)$. SEA: Seto Inland Sea $\left(\rho=1.03 \mathrm{~g} / \mathrm{cm}^{3}\right)$. The middle figures show the heights of the measurement points. The crossings of faults and the survey lines are shown by triangles above the middle figures. The abbreviations of the fault names are the same as in Fig. 1.

Vol. 44, No. 4, 1996 


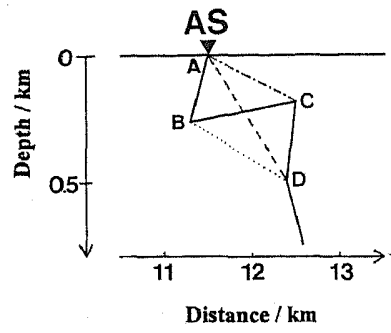

(a)

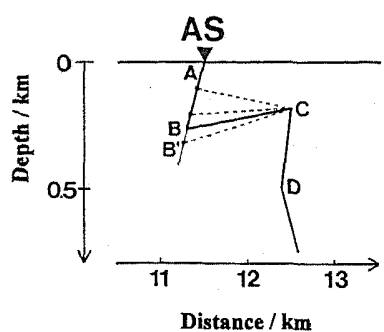

(b)

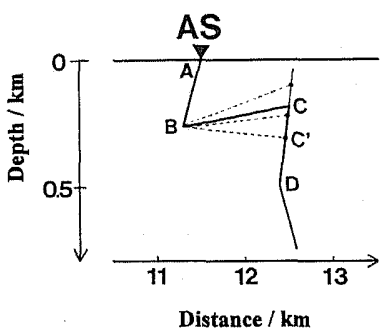

(c)

Fig. 7. Several types of subsurface structures to calculate gravity anomaly in ASHIYAGAWA survey line. Here, we magnify a part just below the Ashiya Fault. The crossing of the Ashiya Fault and the survey line is shown by triangle (AS). (a) Model A-B-C-D is the optimum structure with a hidden fault shown with solid line in Figs. 6(d) and 7(a). Other models assume no hidden fault. Model A-D is shown with a broken line in Figs. 6(d) and 7(a). Model A-B-D and Model A-C-D are represented as a dotted line and a dashed-and-dotted line, respectively, in Fig. 7(a). (b) Variations of Model A-B'-C-D against several depths of point B. (c) Variations of Model A-B-C'-D against several depths of point C.

Table 3. Comparison of variances for several type of structures shown in Fig. $7 \mathrm{a}$.

\begin{tabular}{lcl}
\hline Model & Variance & \multicolumn{1}{c}{ Figure } \\
\hline A-B-C-D & 0.427 & Solid line in Fig. 6(d) \\
A-D & 0.694 & Broken line in Fig. 6(d) \\
A-C-D & 0.791 & \\
A-B-D & 0.749 & \\
\hline
\end{tabular}

Table 4. Variances against depth of point B shown in Fig. 7(b) (Model A-B'-CD).

\begin{tabular}{lll}
\hline Depth of B $(\mathrm{km})$ & Variance & Figure \\
\hline 0.1 & 0.547 & \\
0.15 & 0.494 & \\
0.2 & 0.452 & \\
0.26 & 0.427 & Solid line in Fig. 6(d) \\
0.3 & 0.448 & \\
\hline
\end{tabular}

C (Fig. 7(b) and (c), Tables 4 and 5). As a result, the depths of the hidden fault were determined to be $260 \mathrm{~m}$ (point B) and $180 \mathrm{~m}$ (point C). This suspected fault would be the extension of the Koyo Fault. It is likely that the Koyo Fault extends via this hidden fault to that discovered in the Profile 3 at depth. In contrast, we cannot observe a steep gravity gradient above the Otsuki and Gosukebashi Faults. The reasons will be that such faults have a large right-lateral component rather than a vertical
Table 5. Variances against depth of point $\mathrm{C}$ shown in Fig. 7(c) (Model A-B-C'D).

\begin{tabular}{lll}
\hline Depth of $C(\mathrm{~km})$ & Variance & Figure \\
\hline 0.1 & 0.449 & \\
0.15 & 0.429 & \\
0.18 & 0.427 & Solid line in Fig. 6(d) \\
0.2 & 0.431 & \\
0.25 & 0.452 & \\
\hline
\end{tabular}

one (Research Group for Active Faults in Japan, 1992) and that their fault scarps are not covered by sediment at the crossing with the survey line.

5) NISHINOMIYA survey line: We can observe a slight decrease in gravity around distance $\approx 5 \mathrm{~km}$ in Fig. 6(e), which is caused by the Ashiya Fault scarp covered by sediment. A major gravity gradient is produced by the Koyo Fault at distance $=8.2 \mathrm{~km}$. Both the Ashiya and Koyo Faults must be either reverse or vertical faults to explain the Bouguer anomaly. The vertical displacement of the Koyo Fault just below the surface is estimated as $150 \mathrm{~m}$.

\section{Discussion and Conclusions}

We carried out gravity measurements together with Fast Static GPS positioning across the Rokko Mountains. We estimated the subsurface structure around the Rokko fault system by two-dimensional gravity analysis. Our results are summarized as follows.

1) The optimum surface density of the Rokko 
Table 6. Site names, positions, gravity values, and Bouguer anomalies, which were determined in this survey.

\begin{tabular}{|c|c|c|c|c|c|c|c|}
\hline Site & $\begin{array}{l}\text { Lon } \\
\text { (deg) }\end{array}$ & $\begin{array}{c}\text { Lat } \\
(\mathrm{deg})\end{array}$ & $\begin{array}{c}h \\
(\mathrm{~m})\end{array}$ & $\begin{array}{c}g \\
\text { (mgal) }\end{array}$ & $\begin{array}{c}g_{\mathrm{b}} \\
\text { (mgal) }\end{array}$ & $\begin{array}{c}T_{\mathrm{cl}} \\
\text { (mgal) }\end{array}$ & Remarks \\
\hline 95030601 & 135.2550 & 34.7078 & 3.61 & $979,697.75$ & -8.64 & 0.99 & BM-455 \\
\hline 95030602 & 135.2528 & 34.7093 & 10.09 & $979,697.05$ & -8.02 & 1.07 & GPS \\
\hline 95030603 & 135.2557 & 34.7055 & 3.58 & $979,696.83$ & -9.48 & 0.86 & GPS \\
\hline 95030604 & 135.2518 & 34.7122 & 13.92 & $979,697.54$ & -6.79 & 1.26 & GPS \\
\hline 95030605 & 135.2508 & 34.7145 & 23.75 & $979,696.86$ & -5.47 & 1.42 & GPS \\
\hline 95030606 & 135.2498 & 34.7170 & 34.62 & $979,696.31$ & -3.76 & 1.64 & GPS \\
\hline 95030607 & 135.2480 & 34.7188 & 41.98 & $979,696.50$ & -1.95 & 1.89 & GPS \\
\hline 95030608 & 135.2472 & 34.7205 & 51.99 & $979,696.45$ & 0.16 & 2.12 & GPS \\
\hline 95030609 & 135.2430 & 34.7240 & 94.17 & $979,692.47$ & 5.19 & 2.67 & GPS \\
\hline 95030610 & 135.2423 & 34.7258 & 114.76 & $979,689.08$ & 6.07 & 2.82 & GPS \\
\hline 95030611 & 135.2418 & 34.7280 & 139.61 & $979,684.80$ & 7.14 & 3.20 & GPS \\
\hline 95030612 & 135.2392 & 34.7300 & 184.09 & $979,676.95$ & 8.72 & 3.57 & GPS \\
\hline 95030613 & 135.2373 & 34.7313 & 215.29 & $979,671.06$ & 9.55 & 3.93 & GPS \\
\hline 95030614 & 135.2363 & 34.7323 & 227.70 & $979,668.56$ & 9.97 & 4.35 & GPS \\
\hline 95030615 & 135.2355 & 34.7335 & 241.29 & $979,664.66$ & 10.07 & 5.63 & GPS \\
\hline 95030616 & 135.2335 & 34.7345 & 281.80 & $979,656.30$ & 10.91 & 6.51 & GPS \\
\hline 95030617 & 135.2318 & 34.7368 & 312.74 & $979,649.96$ & 12.05 & 7.76 & GPS \\
\hline 95030618 & 135.2298 & 34.7405 & 442.88 & $979,624.74$ & 11.17 & 5.37 & GPS \\
\hline 95030701 & 135.2328 & 34.7535 & 795.82 & $979,549.85$ & 11.89 & 8.63 & GPS \\
\hline 95030702 & 135.2280 & 34.7457 & 674.70 & $979,574.74$ & 13.02 & 9.43 & GPS \\
\hline 95030703 & 135.2238 & 34.7498 & 762.93 & $979,558.73$ & 12.95 & 7.36 & GPS \\
\hline 95030704 & 135.3140 & 34.7123 & 3.02 & $979,693.21$ & -14.22 & 0.43 & GPS \\
\hline 95030705 & 135.3110 & 34.7168 & 4 & $979,694.47$ & -13.03 & 0.55 & $\mathrm{SH}$ \\
\hline 95030706 & 135.3075 & 34.7198 & 6 & $979,695.24$ & -11.97 & 0.67 & SH \\
\hline 95030707 & 135.3075 & 34.7225 & 10 & $979,695.47$ & -11.06 & 0.75 & SH \\
\hline 95030708 & 135.3063 & 34.7253 & 15 & $979,696.07$ & -9.53 & 0.88 & SH \\
\hline 95030709 & 135.3058 & 34.7282 & 18 & $979,697.29$ & -7.78 & 1.03 & SH \\
\hline 95030710 & 135.3042 & 34.7318 & 27 & $979,698.60$ & -4.59 & 1.33 & GPS \\
\hline 95030711 & 135.3030 & 34.7350 & 36.54 & $979,699.56$ & -1.49 & 1.78 & GPS \\
\hline 95030712 & 135.3018 & 34.7383 & 83 & $979,692.16$ & 0.69 & 2.01 & $\mathrm{SH}$ \\
\hline 95030713 & 135.3005 & 34.7407 & 99.48 & $979,689.52$ & 1.77 & 2.51 & GPS \\
\hline 95030714 & 135.2993 & 34.7428 & 123 & $979,686.50$ & 3.87 & 2.93 & $\mathrm{SH}$ \\
\hline 95030715 & 135.2970 & 34.7448 & 151.80 & $979,681.37$ & 5.38 & 3.77 & GPS \\
\hline 95030716 & 135.2935 & 34.7480 & 219.53 & $979,667.57$ & 6.35 & 4.75 & GPS \\
\hline 95030801 & 135.3130 & 34.7247 & 3.70 & $979,697.75$ & -10.30 & 0.72 & $\mathrm{BM}-458$ \\
\hline 95030802 & 135.2937 & 34.7493 & 236.56 & $979,664.20$ & 6.85 & 5.20 & GPS \\
\hline 95030803 & 135.2930 & 34.7533 & 299.21 & $979,651.57$ & 6.32 & 4.62 & GPS \\
\hline 95030804 & 135.2918 & 34.7557 & 336.73 & $979,644.68$ & 6.28 & 3.88 & GPS \\
\hline 95030805 & 135.2902 & 34.7575 & 365.55 & $979,639.29$ & 6.59 & 3.75 & GPS \\
\hline 95030806 & 135.2888 & 34.7595 & 389.23 & $979,634.51$ & 6.16 & 3.34 & GPS \\
\hline 95030807 & 135.2747 & 34.7683 & 635.17 & $979,583.25$ & 7.70 & 5.75 & GPS \\
\hline 95030808 & 135.2788 & 34.7678 & 549.44 & $979,599.73$ & 6.10 & 5.47 & GPS \\
\hline 95030809 & 135.2817 & 34.7667 & 498.16 & $979,610.62$ & 6.02 & 5.06 & GPS \\
\hline 95030810 & 135.2857 & 34.7652 & 463.09 & $979,619.69$ & 6.25 & 3.39 & GPS \\
\hline 95030811 & 135.2875 & 34.7622 & 415.39 & $979,629.28$ & 6.11 & 3.31 & GPS \\
\hline 95030812 & 135.3672 & 34.7070 & 0.00 & $979,694.06$ & -13.84 & 0.14 & GPS \\
\hline 95030813 & 135.3642 & 34.7107 & 0.00 & $979,694.28$ & -13.91 & 0.16 & GPS \\
\hline 95030814 & 135.3640 & 34.7142 & 1 & $979,694.58$ & -13.69 & 0.17 & $\mathrm{SH}$ \\
\hline 95030815 & 135.3635 & 34.7172 & 1 & $979,695.01$ & -13.50 & 0.18 & $\mathrm{SH}$ \\
\hline
\end{tabular}

Assumed density is $2.40 \mathrm{~g} / \mathrm{cm}^{3}$.

Vol. 44, No. 4, 1996 
Table 6. (continued)

\begin{tabular}{|c|c|c|c|c|c|c|c|}
\hline Site & $\begin{array}{c}\text { Lon } \\
\text { (deg) }\end{array}$ & $\begin{array}{c}\text { Lat } \\
\text { (deg) }\end{array}$ & $\begin{array}{c}h \\
(\mathrm{~m})\end{array}$ & $\begin{array}{c}g \\
\text { (mgal) }\end{array}$ & $\begin{array}{c}g_{\mathrm{b}} \\
\text { (mgal) }\end{array}$ & $\begin{array}{c}T_{\mathrm{cl}} \\
\text { (mgal) }\end{array}$ & Remarks \\
\hline 95030816 & 135.3608 & 34.7198 & 1 & $979,695.46$ & -13.26 & 0.20 & SH \\
\hline 95030817 & 135.3592 & 34.7238 & 0.70 & $979,696.12$ & -12.97 & 0.23 & GPS \\
\hline 95030818 & 135.3562 & 34.7275 & 3.50 & $979,696.28$ & -12.51 & 0.25 & BM-10701 \\
\hline 95030819 & 135.3548 & 34.7305 & 4 & $979,697.13$ & -11.79 & 0.28 & SH \\
\hline 95030820 & 135.3520 & 34.7342 & 3.61 & $979,698.05$ & -11.21 & 0.33 & BM-002-015 \\
\hline 95030902 & 135.3493 & 34.7372 & 4.54 & $979,698.63$ & -10.64 & 0.38 & BM-457 \\
\hline 95030903 & 135.3475 & 34.7400 & 3.25 & $979,699.78$ & -9.94 & 0.44 & GPS \\
\hline 95030904 & 135.3455 & 34.7425 & 3.72 & $979,700.73$ & -9.03 & 0.51 & GPS \\
\hline 95030905 & 135.3440 & 34.7447 & 5.94 & $979,701.28$ & -8.12 & 0.59 & GPS \\
\hline 95030906 & 135.3412 & 34.7468 & 34.10 & $979,696.68$ & -6.99 & 0.67 & GPS \\
\hline 95030907 & 135.3390 & 34.7497 & 39.94 & $979,697.67$ & -4.99 & 0.70 & GPS \\
\hline 95030908 & 135.3375 & 34.7517 & 38.87 & $979,699.34$ & -3.62 & 0.80 & GPS \\
\hline 95030909 & 135.3357 & 34.7535 & 49.55 & $979,699.23$ & -1.54 & 0.93 & GPS \\
\hline 95030910 & 135.3348 & 34.7565 & 36.84 & $979,704.65$ & 1.25 & 1.19 & GPS \\
\hline 95030911 & 135.3312 & 34.7580 & 62 & $979,701.35$ & 3.47 & 1.62 & $\mathrm{SH}$ \\
\hline 95030912 & 135.3318 & 34.7613 & 93.22 & $979,695.19$ & 3.75 & 1.87 & GPS \\
\hline 95030913 & 135.3288 & 34.7643 & 171 & $979,679.92$ & 3.96 & 1.46 & $\mathrm{SH}$ \\
\hline 95030914 & 135.3237 & 34.7682 & 220.94 & $979,669.78$ & 3.91 & 1.51 & GPS \\
\hline 95030915 & 135.3225 & 34.7715 & 228.78 & $979,668.37$ & 3.85 & 1.51 & GPS \\
\hline 95030916 & 135.3185 & 34.7743 & 245.30 & $979,663.47$ & 2.50 & 1.88 & GPS \\
\hline 95030917 & 135.3143 & 34.7778 & 256 & $979,660.45$ & 2.39 & 2.86 & $\mathrm{SH}$ \\
\hline 95030918 & 135.3085 & 34.7790 & 298.54 & $979,651.54$ & 3.97 & 4.62 & GPS \\
\hline 95031002 & 135.0990 & 34.6943 & 138.71 & $979,693.33$ & 16.04 & 0.91 & GPS \\
\hline 95031003 & 135.1025 & 34.6898 & 190.89 & $979,682.94$ & 16.71 & 0.76 & GPS \\
\hline 95031004 & 135.1070 & 34.6863 & 176.26 & $979,686.27$ & 17.15 & 0,61 & GPS \\
\hline 95031005 & 135.1133 & 34.6823 & 117.19 & $979,697.95$ & 16.98 & 0.68 & GPS \\
\hline 95031006 & 135.1167 & 34.6778 & 98.19 & $979,701.08$ & 16.44 & 0.57 & GPS \\
\hline 95031007 & 135.1195 & 34.6723 & 56.63 & $979,709.01$ & 16.75 & 1.10 & GPS \\
\hline 95031008 & 135.1252 & 34.6692 & 52.21 & $979,708.34$ & 16.55 & 2.22 & GPS \\
\hline 95031009 & 135.1262 & 34.6677 & 41 & $979,710.85$ & 16.53 & 1.90 & SH \\
\hline 95031010 & 135.1288 & 34.6657 & 36 & $979,711.45$ & 16.15 & 1.78 & $\mathrm{SH}$ \\
\hline 95031011 & 135.1315 & 34.6642 & 41 & $979,709.94$ & 15.35 & 1.33 & SH \\
\hline 95031012 & 135.1347 & 34.6617 & 32.86 & $979,709.95$ & 13.25 & 0.69 & GPS \\
\hline 95031013 & 135.1363 & 34.6598 & 19.95 & $979,708.10$ & 8.80 & 0.61 & GPS \\
\hline 95031014 & 135.1417 & 34.6518 & 9 & $979,705.94$ & 4.72 & 0.29 & $\mathrm{SH}$ \\
\hline 95031015 & 135.1395 & 34.6540 & 13 & $979,706.12$ & 5.59 & 0.34 & SH \\
\hline 95031016 & 135.1380 & 34.6572 & 16 & $979,707.04$ & 6.99 & 0.46 & $\mathrm{SH}$ \\
\hline 95031017 & 135.1515 & 34.6433 & 3 & $979,704.35$ & 2.49 & 0.17 & SH \\
\hline 95031018 & 135.1477 & 34.6455 & 2 & $979,705.22$ & 2.99 & 0.20 & SH \\
\hline 95031019 & 135.1440 & 34.6493 & 6.16 & $979,705.59$ & 3.95 & 0.24 & GPS \\
\hline 95031101 & 135.2157 & 34.6612 & 6 & $979,696.27$ & -6.42 & 0.23 & $\mathrm{SH}$ \\
\hline 95031102 & 135.2135 & 34.6655 & 9 & $979,696.00$ & -6.38 & 0.28 & SH \\
\hline 95031103 & 135.2100 & 34.6710 & 3 & $979,698.35$ & -5.66 & 0.36 & SH \\
\hline 95031104 & 135.2040 & 34.6812 & 1.28 & $979,701.78$ & -3.25 & 0.55 & GPS \\
\hline 95031105 & 135.2053 & 34.6757 & 1.4 & $979,699.87$ & -4.81 & 0.42 & HS \\
\hline 95031106 & 135.1995 & 34.6842 & 4.69 & $979,703.29$ & -1.17 & 0.67 & BM-452 \\
\hline 95031107 & 135.1958 & 34.6923 & 17 & $979,705.24$ & 3.19 & 1.23 & SH \\
\hline 95031108 & 135.1940 & 34.6948 & 23 & $979,705.49$ & 4.98 & 1.73 & SH \\
\hline 95031109 & 135.1930 & 34.6972 & 45 & $979,702.43$ & 7.07 & 2.52 & SH \\
\hline 95031110 & 135.1832 & 34.7000 & 285.15 & $979,658.50$ & 15.25 & 5.03 & GPS \\
\hline
\end{tabular}


Table 6. (continued)

\begin{tabular}{cccccccc}
\hline Site & $\begin{array}{c}\text { Lon } \\
(\mathrm{deg})\end{array}$ & $\begin{array}{c}\text { Lat } \\
(\mathrm{deg})\end{array}$ & $\begin{array}{c}h \\
(\mathrm{~m})\end{array}$ & $\begin{array}{c}g \\
(\mathrm{mgal})\end{array}$ & $\begin{array}{c}g_{\mathrm{b}} \\
(\mathrm{mgal})\end{array}$ & $\begin{array}{c}T_{\mathrm{cl}} \\
(\mathrm{mgal})\end{array}$ & Remarks \\
\hline 95031111 & 135.1828 & 34.7132 & 333.16 & $979,654.58$ & 17.31 & 2.15 & GPS \\
95031112 & 135.1798 & 34.7173 & 380.13 & $979,644.76$ & 16.69 & 1.95 & GPS \\
95031113 & 135.1858 & 34.7060 & 304.58 & $979,657.99$ & 15.91 & 2.68 & GPS \\
95031114 & 135.1858 & 34.7030 & 337.88 & $979,647.95$ & 15.43 & 5.06 & GPS \\
95031115 & 135.1905 & 34.6963 & 56.40 & $979,701.15$ & 8.16 & 2.45 & GPS \\
95031116 & 135.1977 & 34.6898 & 11 & $979,704.65$ & 1.32 & 0.98 & SH \\
95031117 & 135.1983 & 34.6873 & 7 & $979,704.11$ & 0.01 & 0.83 & C \\
\hline
\end{tabular}

Here, $h$ is the height, $g$ is the gravity, $g_{\mathrm{b}}$ is the Bouguer anomaly $\left(\rho=2.40 \mathrm{~g} / \mathrm{cm}^{3}\right)$, and $T_{\mathrm{cl}}$ is the terrain correction for the land. The abbreviations used in the Remarks column denote the following meanings. GPS, the site position is determined by the GPS fast static method; SH, spot height; HS, height from the sea surface; $\mathrm{C}$, the height is read from contours of a topographical map; TP, triangulation point; BM, benchmark.

granite is $2.40 \mathrm{~g} / \mathrm{cm}^{3}$. This low bulk density suggests that the Rokko granitic rocks are strongly crushed by Quaternary tectonic movements and are deeply weathered to contain abundant groundwater reserves.

2) The regional Bouguer anomaly reveals i) a distinctive belt of steep gravity gradient extending from Awaji Island through the south-flank of the Rokko Mountains to the Arima-Takatsuki tectonic line, ii) two major negative anomalies in the Osaka Plain and the Sanda Basin, which appear to be pushed apart by the intruding Rokko granite represented by high Bouguer anomaly and iii) gradual decrease of gravity anomaly toward the northwest of the Rokko Mountains. We can read the geological history of the Rokko granite and the Kobe and Osaka groups from the regional Bouguer anomaly map.

3) We estimated the subsurface structure around the Rokko fault system along five profiles. We found that most of the Rokko Faults must be either reverse or vertical faults to explain the steep gravity gradient and the thick sediment deposits in the Osaka Plain and Osaka Bay. In contrast, the thickness of sedimentary layer increases gradually to the northwest side of the Rokko Mountains. These features are consistent with tectonic evidence that the Rokko Mountains have been thrust over the Osaka Plain under the westeast compression during the Quaternary and that the "Kinki triangle" (Huzita, 1968) has consequently formed as a tectonic block which is bounded to the northwest by the large-scale, reverse and right-lateral Rokko fault system.
4) We discovered a hidden reverse fault on the extension of the Koyo Fault (Fig. 6(c), (d)). The disaster belt during the Hyogo-ken Nanbu earthquake seemed to be bounded on the north by this hidden subsurface fault (Fig. 8).

5) We found wedge-like soft sediment structure dipping toward the coast (OK in Fig. 6).

We shall now look more carefully into the gravimetric structures from a seismo-tectonic point of view.

First, we would like to point out an interesting relationship between the vertical dislocation of the Hyogo-ken Nanbu earthquake and the structure of the Rokko fault system. The vertical dislocation during the Hyogo-ken Nanbu earthquake on the Honshu side was largest at the Suma Fault and decreased toward the east (e.g., Yoshida et al., 1995; Hashimoto, 1995). On the other hand, the vertical offsets of the faults inferred in this study show a similar tendency. The vertical offset of the Suma Fault is large $(550 \mathrm{~m})$, while those of other faults are smaller (a few hundred meters). We therefore argue that the vertical offsets of faults would reflect recent crustal movements.

Finally, let us discuss the relation between the gravity structure below the Rokko fault system and the cause of the earthquake disaster zone (500$1,500 \mathrm{~m}$ wide), which runs parallel to the surface trace of the Rokko fault system but is significantly shifted from the trace by $1-2 \mathrm{~km}$ toward the coast (Fig. 8). One of the authors (TS) argued for the existence of unknown subsurface faults based on the relation between distribution of building damage, topography, classification of sedimentary deposit, 


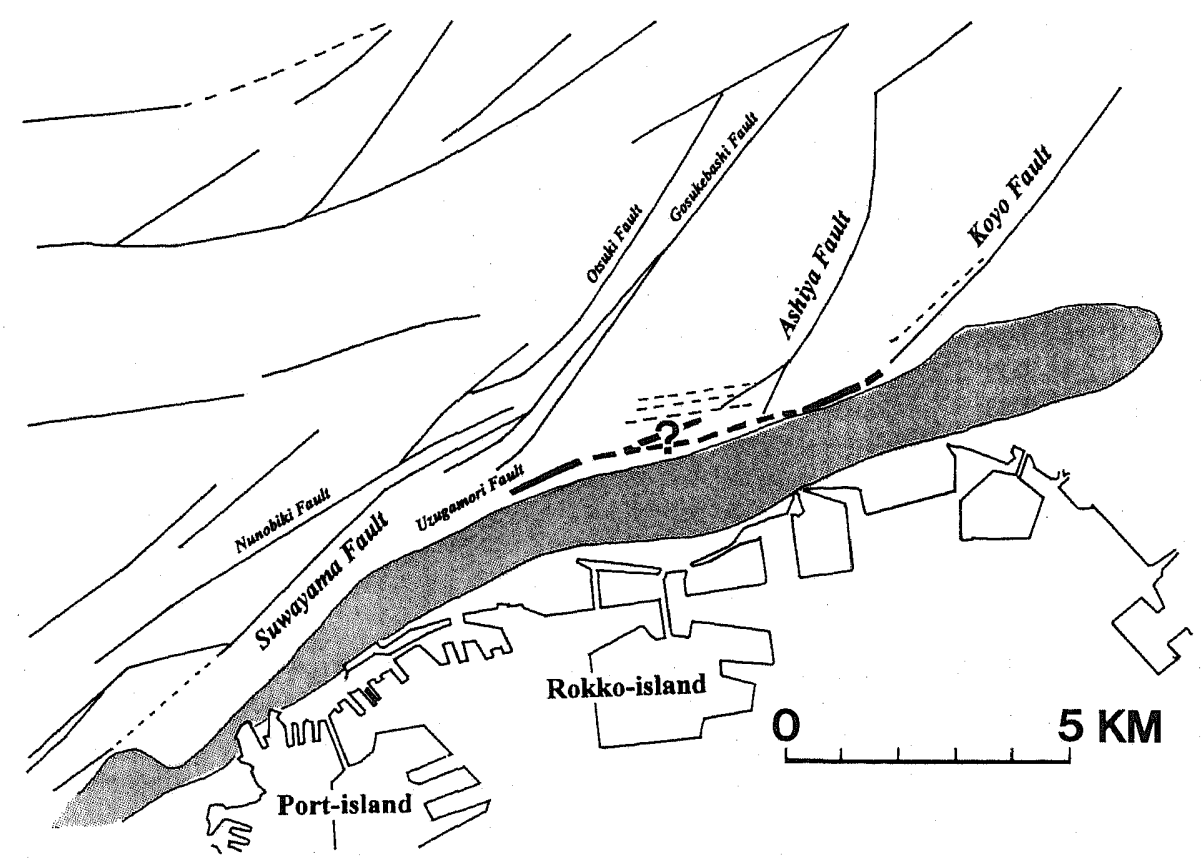

Fig. 8. Distribution of active faults and the earthquake disaster zone. Thin and thick solid curves show surface fault traces and hidden faults inferred from the gravity analysis, respectively. The hatched region indicates the heavily damaged zone of the 1995 Hyogo-ken Nanbu earthquake.

bifurcation pattern of surface trace of active faults and so on (Shimamoto, 1995). In particular, he lays special emphasis on the observation that this disaster belt lies on the extension of the surface faults, that is, the natural extension of the Gosukebashi, Ashiya and Koyo Faults. It is unclear how far the Koyo Fault extends toward the Ashiya Fault by looking at surface geological observations alone. As shown in Fig. 6(d), however, we detected the Koyo Fault extending underground from the surface trace toward the southwest. It follows that the disaster belt is bounded just to the north by the detected subsurface fault. Furthermore, the subsurface fault scarp shown in the ISHIYAGAWA profile (Fig. $6(\mathrm{c})$ ) also seems to be located just on the edge of the disaster belt (Fig. 8).

In addition, there are several independent reports of evidence for the hidden fault. Kikuchi (1995b) estimated ground motion by analyzing video records at many "convenience" stores and inferred the location of the buried fault beneath Kobe City. He showed that the inferred fault trace runs between the heavily damaged zone and the aftershock zone. Ikeda et al. (1995) argued that a hidden fault is buried beneath the disaster belt to explain the first occurence of horizontal motion, recorded as scratch traces on tombstones. Murakami et al. (1995) detected surface deformation associated with the Hyogo-ken Nanbu earthquake by the interferometric technique applied to satellite synthetic aperture radar (SAR) data. They pointed out that according to the SAR data, the seismic fault should lie to the south of the Rokko fault system.

Furthermore, some research groups looked at PS-logging and core boring around the disaster belt, by the reflection method, to obtain evidence for the existence of a subsurface fault. Iwasaki et al. (1995) surveyed on the same line as our ISHIYAGAWA line and discovered an obvious discontinuity of granitic basement which is located near the subsurface fault scarp inferred from the gravity anomaly (Fig. 5(c)), in spite of its surface topography obscurity. Endo et al. (1995) obtained a clear seismic reflection image beneath our ASHIYAGAWA survey line and detected a subsurface reverse fault, whose location corresponds to the fault inferred from the gravity anomaly (Fig. 6(d)) very well. In summary, the several observations above strongly 
support the existence of the subsurface fault as proposed by us.

Alternatively, the disaster belt can also be interpreted in terms of a focusing effect of seismic rays incident upward through the wedge-like soft sediment layer dipping toward the coast. Pitarka $e t$ al. (1995) showed the amplification of seismic rays by simulation of strong motions. In particular, they demonstrated that an effective amplification in a narrow region (i.e. heavily damaged zone) results from the basin edge structure adjacent to the hidden fault in the ASHIYAGAWA line. In addition, his simulation explains the remarkable difference between the S-P time delay of seismic wave on the Rokko granitic layer and that on the disaster belt (0.7-0.9s) (Iwata et al., 1995). Our subsurface structures show a wedge-like sediment layer (the Osaka and Kobe groups), which is consistent with this expectation. Our models based on gravity analysis, even though ignoring depth-dependence of density within the rock bodies, will pose a critical constraint on such simulations to reveal the focusing effect around the Rokko fault system.

We would like to express our sincere thanks to the Geographical Survey Institute, Japan for providing gravity data of the studied area. We also thank anonymous reviewers for their helpful comments on the manuscript.

\section{REFERENCES}

Beutler, G., W. Gurtner, M. Rothacher, U. Wild, and E. Frei, Relative static positioning with the Global Positioning System: basic technical considerations, in Global Positioning System: An Overview, International Association of Geodesy Symposium 102, ed. Y. Bock and N. Leppard, pp. 1-23, Springer Verlag, New York, 1990.

Endo, H., S. Watanabe, M. Makino, Y. Murata, K. Watanabe, and A. Urabe, Subsurface geological structure across the severely damaged zone caused by the 1995 south Hyogo earthquake, J. Geol. Soc. Jpn., 101, 1995 (in Japanese).

Gravity Research Group in Southwest Japan, A Bouguer gravity anomaly map in Central Japan, Rep. Geol. Surv. Jpn., 280, 29-36, 1994.

Hagiwara, Y., Conventional and spherical Bouguer correction, J. Geod. Soc. Jpn., 21, 16-18, 1975 (in Japanese).

Hashimoto, M., Geophysical image of the 1995 HyogokenNanbu earthquake, Kokudochiriin Jihou, 83, 6-14, 1995 (in Japanese).

Hoffman-Wellenhof, B., H. Lichtenegger, and J. Collins,
Global Positioning System: Theory and Practice, Springer Verlag, Wien, 1992.

Huzita, K., Rokko Movements and its appearance, $Q$. Res., 7, 248-260, 1968 (in Japanese with English abstract).

Huzita, K., T. Kasama, M. Hirano, T. Shinoda, and M. Tanaka, Geology and geomorphology of the Rokko area, Kinki District, Japan, J. Geosci. Osaka Univ., 14, 71-124, 1971.

Ikebe, N. and K. Huzita, The Rokko movements, the Plio-Pleistocene crustal movements in Japan, Quaternaria, 8, 277-287, 1966.

Ikeda, Y., M. Togo, S. Sawa, S. Kato, and S. Kumamoto, Behavior of subsurface seismic fault and distribution of first arrival motion estimated by scratch traces on tombstones, Abstracts of rapid Communication on the 1995 Hyogo-ken Nanbu Earthquake, 45-46, 1995 (in Japanese)

Inoue, $\mathrm{H}$., A least-squares smooth fitting for irregularly spaced data: Finite element approach using the cubic B-spline basis, Geophysics, 51, 2051-2066, 1986.

Ishikawa, K., S. Mizoguchi, and A. Oshika, Geology in Kobe area and investigation of the disaster on the 1995 south Hyogo great earthquake, J. Jpn. Soc. Engineer. Geol., 36, 62-80, 1995 (in Japanese with English abstract).

Ito, K., H. Murakami, and K. Nakamura, Gravity survey in the vicinity of the Arima-Takatsuki tectonic line, Zisin 2, 42, 485-495, 1989 (in Japanese with English abstract).

Iwasaki, Y., T. Hongo, H. Yokota, and S. Ito, Ground characteristics of the Rokko-Dai, Prog. Abstr. Seismol. Soc. Jpn., 2, 1995 (in Japanese with English abstract).

Iwata, T., K. Hatayama, H. Kawase, K. Irikura, and K. Matsunami, Array observation of aftershocks of the 1995 Hyogoken-nanbu earthquake at Higashinada ward, Kobe city, J. Nat. Disast. Sci., 16, 41-48, 1995.

Kamae, $\mathrm{K}$. and $\mathrm{K}$. Irikura, A fault rupture model of the 1995 Hyogoken Nanbu earthquake $\left(M_{\mathrm{IMA}}=7.2\right)$ estimated by the empirical Green's function method, $J$. Nat. Disast. Sci., 16, 31-40, 1995.

Kikuchi, M., Source process of the 1995 Hyogoken-nanbu earthquake. Preliminary analysis of teleseismic body waves, Chishitsu News (Geol. News), 486, 12-15, 1995a (in Japanese).

Kikuchi, M., A shopping trolley seismograph, Nature, 377, 19, 1995b.

Motosaka, M. and M. Nagano, Analytical study on amplification characteristics of ground motions taking account of irregular bedrock structure in Kobe city, Tsuchi to Kiso, 43, 15-20, 1995 (in Japanese).

Murakami, M., S. Fujiwara, and T. Saito, Detection of crustal deformations associated with the 1995 Hyogo- 
ken-Nanbu earthquake by interferometric SAR, Kokudochiriin Jihou, 83, 24-27, 1995 (in Japanese).

Nakata, T., K. Yomogida, J. Okada, T. Sakamoto, K. Asahi, and N. Chida, Surface fault ruptures associated with the 1995 Hyogoken-Nanbu earthquake, J. Geogr., 104, 127-142, 1995 (in Japanese with English abstract).

Pitarka, A., K. Irikura, T. Iwata, and T. Kagawa, Basin structure effects in the Kobe area inferred from the modeling of ground motions from two aftershocks of the January 17, 1995 Hyogo-ken Nanbu earthquake, $J$. Phys. Earth, 44, 563-576, 1996.

Research Group for Active Faults of Japan, Active Faults in Japan, Univ. of Tokyo Press, Tokyo, 1992.

Shichi, R. and H. Aoki, Gravity anomaly around the focal region of the Hyogoken-Nanbu earthquake, Chikyuu Monthly (Suppl.), 13, 129-134, 1995 (in Japanese).

Shimamoto, T., Mystery of 'earthquake disaster belt,' Kagaku (Science), 65, 195-198, 1995 (in Japanese).
Talwani, M., J. Lamar Worzel, and M. Landisman, Rapid gravity computations for two-dimensional bodies with application to the Mendocino submarine fracture zone, J. Geophys. Res., 64, 49-59, 1959.

Tobita, M., Development of coordinate transformation program TKY2WGS, Tech. Memorandum Geogr. Survey Inst., B.1, 22, 1-7, 1994.

Trimble Navigation, GPS Surveyor's Field Guide, Trimble Navigation Ltd., Sunnyvale, 1992.

Yamamoto, A., K. Nozaki, Y. Fukao, M. Furumoto, R. Shichi, and T. Ezaka, Gravity survey in the central ranges, Honshu Japan, J. Phys. Earth, 30, 201-243, 1982.

Yoshida, S., K. Koketsu, T. Shibasaki, T. Sagiya, and Y. Yoshida, Joint inversion of near- and far-field waveforms and geodetic data for the rupture process of the Hyogoken-nanbu earthquake, Prog. Abstr. Seismol. Soc. Jpn., 2, 1995 (in Japanese). 